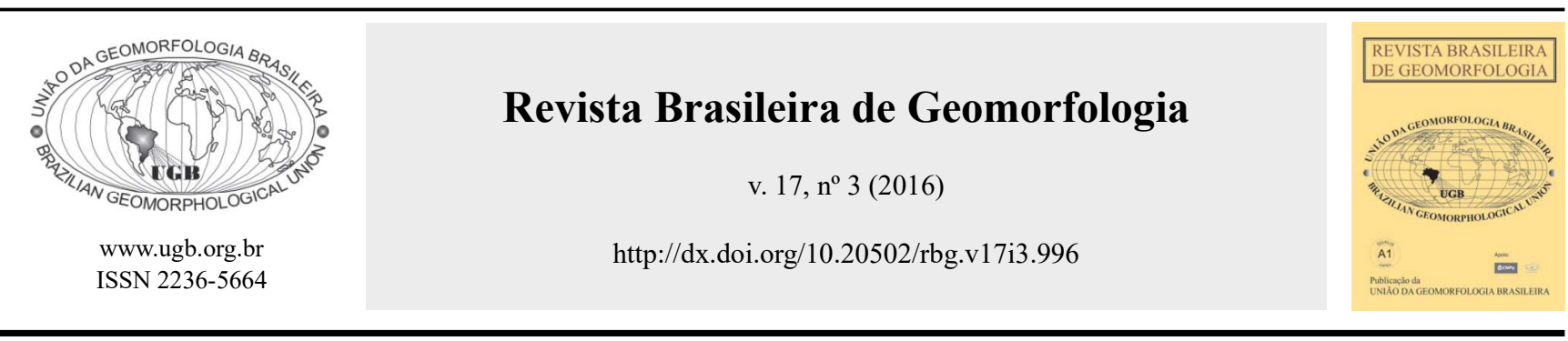

\title{
INFLUÊNCIA NEOTECTÔNICA NO ESTABELECIMENTO DOS VALES DOS RIOS PARAIÍBA E MAMANGUAPE, NORTE DA BACIA PARAIÍBA(PB)
}

\section{NEOTECTONIC INFLUENCE ON THE ESTABLISHMENT OF THE PARAÍBA AND MAMANGUAPE RIVER VALLEYS, NORTHERN PARAIÍBA BASIN (PB)}

Fabio Corrêa Alves

Divisão de Sensoriamento Remoto, Instituto Nacional de Pesquisas Espaciais Av. dos Astronautas, 1758, São José dos Campos, São Paulo, CEP: 12.245-970, Brasil

Email:alves.fabioc@gmail.com

Dilce de Fátima Rossetti

Divisão de Sensoriamento Remoto, Instituto Nacional de Pesquisas Espaciais Av. dos Astronautas, 1758, São José dos Campos, São Paulo, CEP: 12.245-970, Brasil

Email:rossetti@dsr.inpe.br

\begin{tabular}{l} 
Informações sobre o Artigo \\
\hline Recebido (Received): \\
26/01/2016 \\
Aceito (Accepted): \\
25/05/2016
\end{tabular}

\section{Palavras-chave:}

Neotectônica; Neógeno;

Pleistoceno Tardio-Holoceno.

\section{Keywords:}

Neotectonics; Neogene; Late Pleistocene-Holocene.

\begin{abstract}
Resumo:
Evidências geológicas e geomorfológicas de atividade neotectônica têm sido crescentes em diversas áreas do nordeste brasileiro, apesar dessa região ser considerada como tectonicamente estável, dada sua localização na margem passiva da placa Sulamericana. Grande parte desse registro neotectônico ocorre na Bacia Paraíba, caracterizada por altos e baixos topográficos e por sistemas de drenagem com feições anômalas. Publicações prévias propuseram que cursos fluviais terminais desta bacia, como é o caso dos rios Paraíba e Mamanguape, estão confinados a grabens. Porém, faltam dados geológicos e geomorfológicos que comprovem essa interpretação. Este trabalho reúne informações estratigráficas de subsuperfície com dados morfoestruturais que permitem sustentar a hipótese de controle neotectônico no desenvolvimento dos cursos terminais dos rios Paraíba e Mamanguape. Para isso, a análise morfoestrutural derivada de produtos de sensoriamento remoto foi integrada com a correlação estratigráfica regional com base em dados de subsuperfície. A análise morfoestrutural revelou lineamentos compatíveis com a orientação de estruturas tectônicas regionais dominantes no nordeste brasileiro, bem como uma variedade de anomalias de drenagem. A correlação estratigráfica mostrou variações expressivas nas espessuras dos estratos sedimentares em curtas distâncias, que são sugestivas de falhas. Atividades tectônicas teriam ocorrido no Neógeno, ou seja, durante a deposição da Formação Barreiras, bem como no Quaternário tardio, após a deposição dos Sedimentos PósBarreiras. Portanto, o mais provável é que o estabelecimento dos vales fluviais dos rios Paraíba e Mamanguape tenha ocorrido em grabens formados por reativações de falhas pré-existentes no embasamento précambriano.
\end{abstract}




\section{Abstract:}

Geomorphological and geological evidences of neotectonic activity have increased in several areas of northeastern Brazil, despite that this region is regarded as tectonically stable due to its location in the passive margin of the South American plate. The majority of this neotectonic record occurs in the Paraíba Basin, which is characterized by topographic highs and lows and by drainage systems with anomalous features. Previous studies have proposed that terminal rivers in this basin, such as the Mamanguape and Paraíba Rivers, are confined to grabens. However, there is still an overall lack of geomorphological and geological data to support this interpretation. This work integrates subsurface stratigraphic information and morphostructural data that allow to support the hypothesis of neotectonic control on the development of the terminal courses of the Mamanguape and Paraíba Rivers. To approach this issue, morphostructural analysis derived from remote sensing products was integrated with stratigraphic data. The morphostructural analysis revealed lineaments consistent with the regional tectonic trends that prevail in northeastern Brazil, as well as a variety of drainage anomalies. The stratigraphic correlation showed significant variation in the thicknesses of the sedimentary strata at short distances suggestive of faults. Tectonic activity would have occurred during the deposition of the Barreiras Formation in the Neogene and after the deposition of the Post-Barreiras Sediments in the late Quaternary. Therefore, the most likely is that the establishment of the Paraíba and Mamanguape river valleys occurred in grabens formed by reactivation of faults pre-existing in the Precambrian basement.

\section{Introdução}

$\mathrm{O}$ registro de atividade neotectônica tem sido crescente em diversas áreas do nordeste brasileiro, apesar dessa região ter sido considerada, por muito tempo, como tectonicamente estável desde o final do Mesozóico, dada sua localização na margem passiva da placa Sulamericana (BEZERRA e VITA FINZI, 2000). Parte do registro neotectônico ocorre na porção emersa da Bacia Paraíba, onde um número expressivo de estruturas tectônicas, como falhas e dobras, ocorre em depósitos sedimentares neógenos e quaternários. Tais estruturas afetam o relevo da bacia, que é caracterizado por altos e baixos topográficos. Elas também influenciam os sistemas de drenagem sob forma de anomalias morfoestruturais já documentadas em publicações anteriores (p.e., BRITO NEVES et al., 2004, 2009; FURRIER et al., 2006; LIMA FILHO et al., 2006; BEZERRA et al., 2008, 2014; ROSSETTI et al., 2009, 2011a, 2011b; ANDRADES FILHO 2014; ALVES e ROSSETTI, 2015). Em particular, sistemas fluviais da Bacia Paraíba possuem canais principais confinados a grabens, como verificado nas porções terminais dos rios Paraíba e Mamanguape (BRITO NEVES et al., 2004, 2009; FURRIER et al., 2006; BEZERRA et al., 2008, 2014). Porém, falta ainda uma análise morfoestrutural detalhada desses dois sistemas fluviais a fim de comprovar essa hipótese. Além disso, as publicações disponíveis utilizaram sobretudo informações morfológicas, não havendo ainda estudos geológicos com base, por exemplo, na correlação estratigráfica regional das unidades sedimentares em subsuperfície que possam suportar melhor as interpretações de influência da neotectônica no desenvolvimento dos cursos fluviais dessa bacia.

Por formarem as maiores bacias de drenagem da Bacia Paraíba, os rios Paraíba e Mamanguape são de interesse especial em investigações morfoestruturais visando verificar o efeito tectônico na evolução da paisagem do nordeste brasileiro. A análise morfoestrutural baseada em elementos da drenagem e do relevo é favorecida pelo uso de diversos produtos e técnicas de sensoriamento remoto. Estruturas tectônicas, como falhas e dobras, têm sido reconhecidas com base na análise detalhada de padrões e anomalias de drenagem, bem como na interpretação de lineamentos morfoestruturais extraídos da drenagem e do relevo (p.e., HOWARD, 1967; O'LEARY et al., 1976; DEFFONTAINES e CHOROWICZ, 1991). A análise desses elementos morfoestruturais tem sido feita principalmente a partir de imagens derivadas de multissensores ópticos. Entretanto, o uso de imagens ópticas em áreas tropicais, como é o caso da costa nordeste brasileira, é desfavorecido pela frequente cobertura de nuvens.

Nesta última última década, a abordagem morfoestrutural vem sendo executada com auxílio de modelos digitais de elevação (MDE's), como o derivado da Shuttle Radar Topography Mission (SRTM), adquirido na banda $\mathrm{C}(5,6 \mathrm{~cm})$ por interferometria de radar de abertura sintética (inSAR) (RABUS et al., 2003). No caso da região 
nordeste do Brasil, vários estudos morfoestruturais foram realizados com base integralmente no MDE-SRTM (p.e., FURRIER et al., 2006; BEZERRA et al., 2008; ROSSETTI et al., 2011b; ANDRADES FILHO e ROSSETTI, 2012a, 2012b; MAIA e BEZERRA, 2013, 2014; ALVES e ROSSETTI, 2015).

Além da disponibilidade de novos produtos de sensoriamento remoto, como o MDE-SRTM, a Bacia Paraíba possui um grande número de informações de subsuperfície derivadas de sondagens feitas para prospecção de água subterrânea. A análise desses dados pode disponibilizar informações geológicas, principalmente correlações estratigráficas de unidades sedimentares. Juntamente com dados de sensoriamento remoto, essas informações podem contribuir para a análise da influência tectônica no desenvolvimento dos vales fluviais.

O objetivo do presente trabalho foi verificar a hipótese de influência neotectônica no desenvolvimento dos vales dos rios Paraíba e Mamanguape, integrando dados morfoestruturais e geológicos derivados da análise de dados do MDE-SRTM e da correlação de dados de subsuperfície adquiridos por sondagem. Informações de campo incluíram a análise da morfologia local e a descrição de afloramentos em corte de estradas. Adicionalmente, adquiriu-se testemunhos rasos de sedimentos representativos da planície aluvial dos rios analisados, com obtenção de amostras para datação, o que contribuiu tanto para a interpretação das unidades sedimentares em subsuperfície, como para a discussão dos estágios finais de preenchimento dos vales desses rios. Embora ainda em número limitado, os dados geológicos de subsuperfície apresentados neste trabalho constituem o primeiro registro da sucessão sedimentar dos vales dos rios Paraíba e Mamanguape.

\section{Fisiografia e contexto geológico}

A área de estudo possui $3107,7 \mathrm{~km}^{2}$ e está localizada na porção oriental do Estado da Paraíba, Nordeste do Brasil (Figura 1A). Os sistemas fluviais principais encontrados nessa região ocorrem em sua porção oeste, sendo dominados pelas bacias hidrográficas dos cursos inferiores dos rios Paraíba e Mamanguape. Esses rios escoam para o Oceano Atlântico, sendo orientados preferencialmente na direção SW-NE, seguindo a orientação geral dos lineamentos regionais da porção oriental do nordeste brasileiro (Figura 1B-C).
Em sua porção oeste, a área de estudo é constituída por rochas gnáissicas e migmatíticas précambrianas (Figura 1B-C), que faz parte dos terrenos deformados da Província Estrutural Borborema (ALMEIDA et al., 2000; BRITO NEVES et al., 2009). Para leste, sobre o embasamento cristalino, se estabeleceu a Bacia Paraíba, que é limitada pela falha de Mamanguape a norte e pelo lineamento Pernambuco a sul (Figura 1B). As etapas de preenchimento sedimentar desta bacia iniciaram-se no final do Mesozóico e se estenderam até o Quaternário, com as formações Beberibe, Itamaracá, Gramame, Maria Farinha, Barreiras (BARBOSA et al., 2003) e os Sedimentos Pós-Barreiras (ROSSETTI et al., 2012). As unidades sedimentares expostas em superfície na área de estudo, que está situada na porção norte emersa da Bacia Paraíba, incluem apenas a Formação Barreiras (BARBOSA et al., 2003) e os Sedimentos Pós-Barreiras (ROSSETTI et al., 2012) (Figura 1C), ambos representados por unidades siliciclásticas consistindo em arenitos, argilitos e depósitos heterolíticos, além de conglomerados. A Formação Barreiras, de idade miocênica (p.e., ROSSETTI et al., 2013), foi primeiramente atribuída a ambientes essencialmente continentais dos tipos fluvial entrelaçado e leques aluviais (ARAÚJO et al., 2006; MORAIS et al., 2006). Essa unidade foi reinterpretada como contendo depósitos formados em ambientes litorâneos influenciados por correntes de maré (ROSSETTI et al., 1990). Exposições da Formação Barreiras ocorrem em pequenas áreas em superfície na totalidade da área de estudo (Figura 1C).

Os Sedimentos Pós-Barreiras, de idade pleistocênica tardia a holocênica, ocorrem com maior representatividade na área de estudo (Figura 1C), sendo constituídos por dois intervalos estratigráficos, designados informalmente de PB1 e PB2 (ROSSETTI et al., 2012). A unidade PB1 é pleistocênica tardia e inclui arenitos intercalados com argilitos e conglomerados, comumente associados a concreções de laterita. Esses depósitos registram processos fluviais, de fluxos gravitacionais subaéreos e, localmente, marinhos (ROSSETTI et al., 2012; GANDINI et al., 2014). A unidade PB2 é principalmente holocênica, sendo constituída por sedimentos arenosos, em geral maciços. Além dessas duas unidades sedimentares, também são encontrados sedimentos aluviais recentes (Holoceno tardio), associados aos rios principais da área de estudo (Figura 1C). 

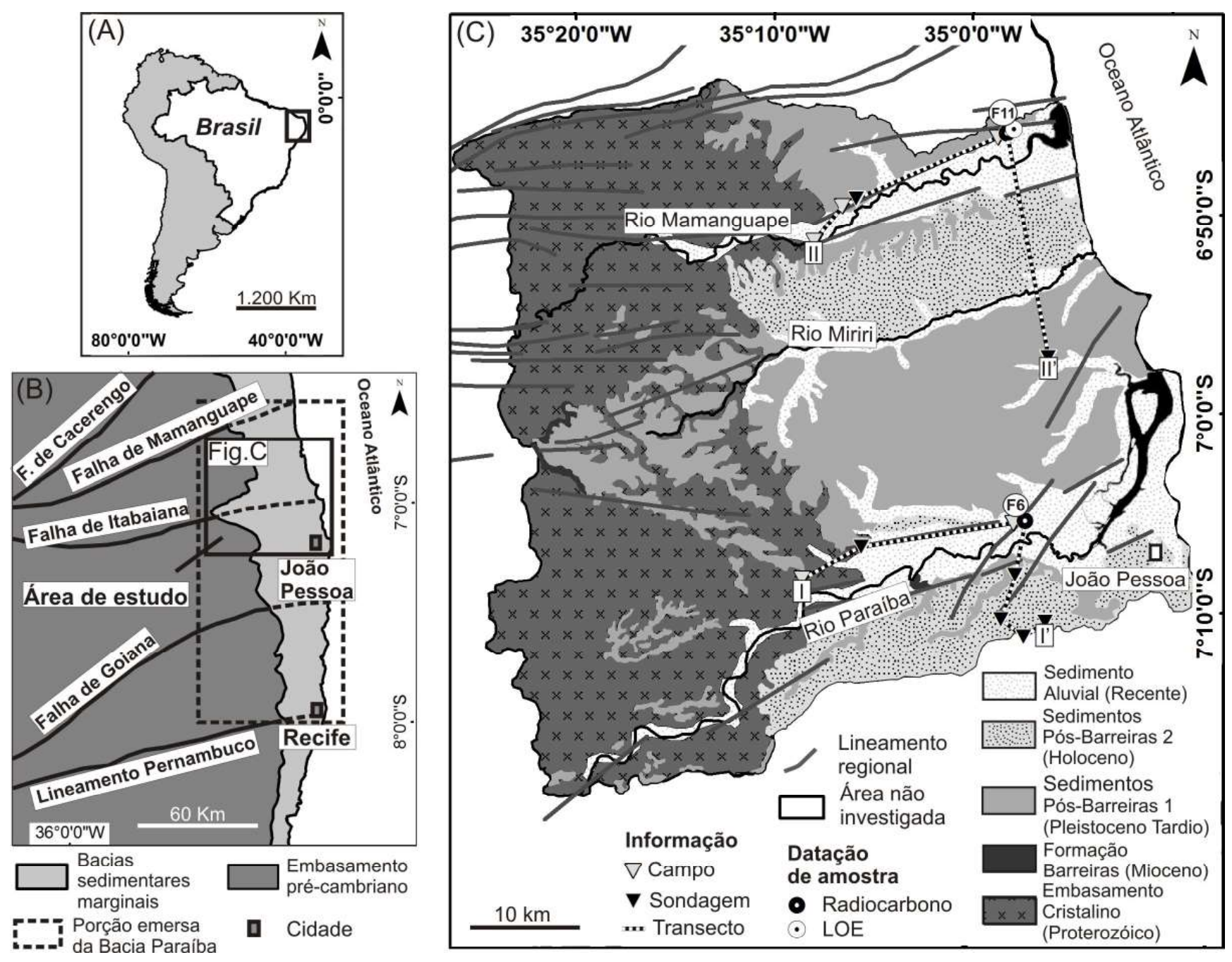

Figura 1 - Localização da área de estudo no nordeste brasileiro (A) e seu arcabouço geológico, incluindo estruturas tectônicas principais (B). (C) Mapa geológico da área de estudo, com lineamentos regionais e localização de amostras de sedimentos submetidas à datação por radiocarbono e luminescência opticamente estimulada (LOE). Também inclusa está a localização de dados de sondagem e afloramentos utilizados nesse trabalho, bem como de transectos representativos das correlações estratigráficas realizadas ao longo dos vales dos rios Paraíba (I-I') e Mamanguape (II-II'). Fonte: Mapa geológico: adaptado de Rossetti et al. (2012); lineamentos regionais: adaptado de Barbosa et al. (2003), Brito Neves et al. (2004, 2009), Bezerra et al. (2008, 2014).

\section{Materiais e Métodos}

Os materiais utilizados no presente trabalho incluíram: (i) dados vetoriais georreferenciados da rede de drenagem e bacias hidrográficas derivadas de cartas topográficas em escala 1:100.000 (acesso em: http:// www.aesa.pb.gov.br/); (ii) MDE-SRTM de resolução espacial $30 \mathrm{~m}$ e variáveis geomorfométricas de curvatura horizontal e orientação de vertentes derivadas do projeto TOPODATA (acesso em: http://www.dpi. inpe.br/topodata); (iii) variável geomorfométrica de coerência topográfica (VALERIANO e ROSSETTI, 2011); (iv) informações geológicas (p.e., ROSSETTI et al., 2012) e estruturais (p.e., BARBOSA et al., 2003; BRITO NEVES et al., 2004, 2009; BEZERRA et al., 2008, 2014); e (v) dados de sondagens obtidos do acervo da empresa Hidrotec - Poços Artesianos e de projetos do Serviço Geológico do Brasil - Companhia de Pesquisa de Recursos Minerais (CPRM) (CPRM, 2001).

Dados vetoriais georreferenciados da rede de drenagem e do relevo foram utilizados para a caracterização morfoestrutural. A rede de drenagem foi extraída pela integração da base vetorial derivada de cartas topográficas com o MDE-SRTM de resolução 
espacial de $30 \mathrm{~m}$ e da coerência topográfica. Esses dados foram ajustados manualmente, isto é, complementados e corrigidos, quando necessários, por interpretação visual e edição vetorial com auxílio do aplicativo ArcGIS 10. Foram aplicadas paletas de cores e operações de relevo sombreado no MDE-SRTM, a fim de realçar canais de drenagem e morfologias do relevo. A variável coerência topográfica foi gerada pela decomposição do produto orientação de vertentes em senos e cossenos, integração dessas componentes por filtragem de média em janela móvel de dimensão $7 \mathrm{x} 7$ e cálculo da componente resultante para uma determinada área de pixels (VALERIANO e ROSSETTI, 2011). Com a base vetorial da drenagem corrigida, foi possível a identificação visual de anomalias de drenagem de maior expressividade, tendo como base exemplos disponíveis na literatura (HOWARD, 1967; DEFFONTAINES e CHOROWICZ, 1991).

Lineamentos morfoestruturais foram extraídos pela integração da base vetorial da drenagem com as variáveis geomorfométricas locais de curvatura horizontal e orientação de vertentes, estas derivadas do projeto TOPODATA (VALERIANO e ROSSETTI, 2012). Para uma melhor interpretação dos lineamentos em superfície, a variável orientação de vertentes foi associada a uma paleta circular em níveis de cinza, dada sua natureza circular (VALERIANO, 2007). Os lineamentos morfoestruturais foram vetorizados em escala fixa de 1:100.000, com mapeamento de lineamentos de comprimentos $\geq 2 \mathrm{~cm}$. O direcionamento dos lineamentos morfoestruturais foi analisado em diagramas de roseta, utilizando a frequência absoluta (número absoluto de lineamentos) em intervalos de $10^{\circ}$ azimutais.

Informações extraídas com base nos produtos de sensoriamento remoto foram complementadas com observações de campo. Estas incluíram descrições, com registros fotográficos, de feições do relevo visando validar interpretações das estruturas sugeridas nos produtos de sensoriamento remoto. Adicionalmente, também foram adquiridos dois testemunhos sedimentares com trado holandês, que serviram para descrever as sucessões sedimentares representativas dos estágios finais de desenvolvimento da planície dos rios Paraíba e Mamanguape. Esses testemunhos foram coletados na profundidade de até $5,20 \mathrm{~m}$ (perfis F6 e F11 na Figura 5), sendo sua distribuição litológica vertical devidamente anotada em perfis litoestratigráficos. Os testemunhos serviram, ainda, para a coleta de amostras para datações por radiocarbono e luminescência opticamente estimulada (LOE). Para a datação por radiocarbono foram coletadas sete amostras de litologias argilosas correspondentes à planícies dos rios Paraíba (perfil F6) e Mamanguape (perfil F11) (pontos pretos na Figura 1C), com profundidades de até 4,75 m. Essas datações foram realizadas no Beta Laboratory Ltd, em Miami, Florida. As idades convencionais foram calibradas para o calendário atual utilizando o aplicativo Calib v. 7.1. Apenas uma amostra foi submetida à datação pela técnica de LOE. Esta amostra deriva de sedimentos arenosos da base do perfil litoestratigráfico da planície do rio Mamanguape (perfil F11) (ponto branco na Figura 1C). A coleta foi feita a 2,70 $\mathrm{m}$ de profundidade utilizando-se tubos plásticos do tipo PVC, para proteção contra a radiação solar. As análises de dose equivalente (Gy) e taxa de dose anual ( $\mathrm{Gy} / \mathrm{ka}$ ) foram realizadas no Laboratório de Espectrometria Gama e Luminescência (LEGAL) do Instituto de Geociências (IGc) da Universidade de São Paulo (USP). Em ambos os casos, foram utilizadas etapas estabelecidas no protocolo Single-Aliquot Regenerative-Dose (SAR) (MURRAY e WINTLE, 2000; WINTLE e MURRAY, 2006).

Para a correlação estratigráfica regional, procedeu-se com a interpretação de sete perfis litoestratigráficos de subsuperfície (Figura 1C). Quatro desses perfis foram obtidos do acervo da empresa Hidrotec, enquanto, três derivam de projetos da CPRM (CPRM, 2001). Devido à ausência de informações sedimentares complementares para uma melhor discriminação das unidades sedimentares em subsuperfície, as informações contidas nesses perfis foram agrupadas em quatro unidades geológicas de interesse: (i) sedimentos aluviais; (ii) Sedimentos Pós-Barreiras/Formação Barreiras; (iii) Formação Gramame/Maria Farinha; e (iv) embasamento cristalino. Os dados de subsuperfície tiveram suas coordenadas plotadas em Sistema de Informação Geográfica (SIG), com auxílio do aplicativo ArcGIS 10. Com base na disposição espacial desses dados em superfície foi possível à elaboração de dois transectos (linhas tracejadas na Figura 1C). Esses transectos foram combinados com perfis topográficos extraídos do MDE-SRTM e manipulados em aplicativo de edição gráfica. 


\section{Resultados}

\section{Caracterização morfoestrutural das bacias de drenagem}

Os sistemas hidrográficos dominantes na área de estudo consistem nas bacias dos baixos cursos dos rios $\mathrm{Pa}$ raíba e Mamanguape (Figura 2A). Rochas précambrianas do embasamento cristalino predominam na porção oeste dessas duas bacias, e, localmente, ocorre a Formação
Barreiras (Figuras 1C e 2A). Para leste, há predomínio dos Sedimentos Pós-Barreiras 1 e 2, além de extensa cobertura de sedimentos aluviais recentes que recobrem os vales dos rios Paraíba e Mamanguape (Figuras 1C e 2A).

A bacia do baixo curso do rio Paraíba possui área de $1.753 \mathrm{~km}^{2}$. Ao longo dessa área, o rio Paraíba se estende por aproximadamente $75 \mathrm{~km}$ de extensão, fluindo de SW para NE, com inflexão para norte próximo à sua

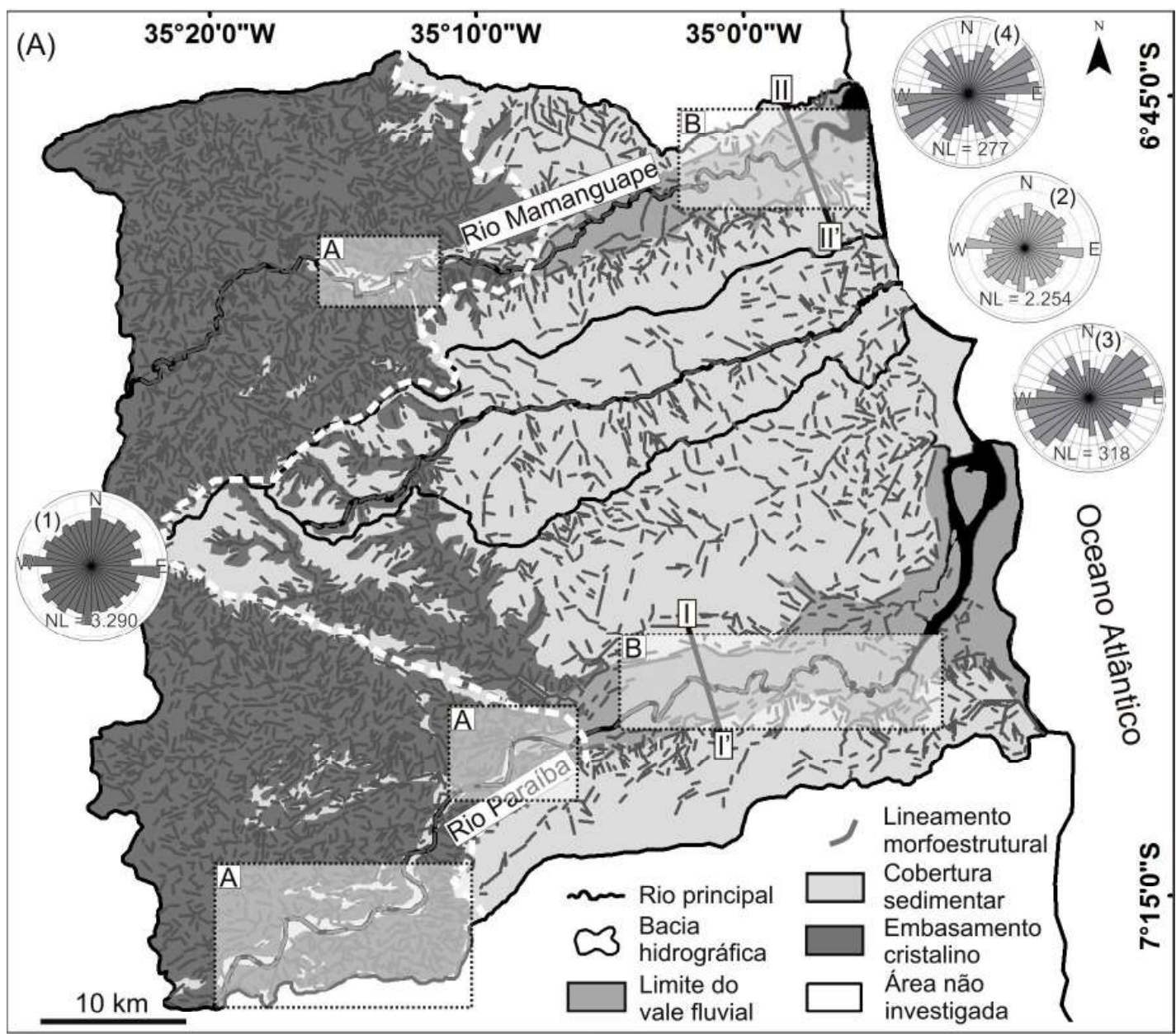

(B)

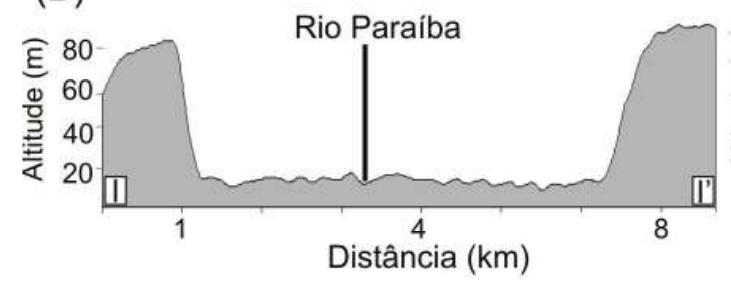

(C)

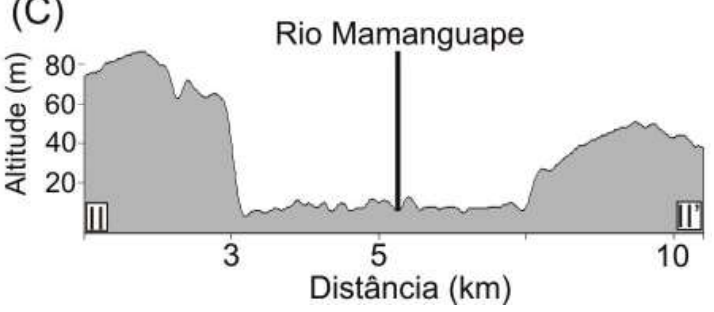

Figura 2 - (A) Caracterização morfoestrutural das bacias dos rios Paraíba e Mamanguape em áreas de cobertura sedimentar e de embasamento cristalino précambriano, com indicação de anomalias de drenagem $(A=$ inflexão em ângulo reto a obtuso; $B=$ meandro isolado e comprimido; linha tracejada branca = limite entre embasamento cristalino a oeste e depósitos sedimentares a leste). Também inclusos estão os lineamentos morfoestruturais e os diagramas de roseta, extraídos sobre áreas do embasamento cristalino (1), cobertura sedimentar (2) e ao longo dos vales fluviais dos rios Paraíba (3) e Mamanguape (4) ( $N L$ = número total de lineamentos). (B-C) Perfis topográficos sobre os vales dos rios Paraíba (B) e Mamanguape (C) elaborados a partir de MDE-SRTM com resolução espacial de $30 \mathrm{~m}$ (ver localização dos perfis em A). 
desembocadura (Figuras 1C e 2A). A bacia hidrográfica do baixo curso do rio Mamanguape possui área de $1.008 \mathrm{~km}^{2}$. Os rios Paraíba e Mamanguape apresentam vales amplos (i.e., larguras médias de 6,7 e 5,7 km para os rios Paraíba e Mamanguape, respectivamente), com planícies de inundação mais expressivas relativamente a seus cursos atuais, que são restritos a canais com menos de $100 \mathrm{~m}$ de largura antes de sua amplificação nas zonas estuarinas (Figuras 2B-C e 1C).

Anomalias de drenagem foram registradas nas duas bacias de drenagem analisadas, sendo as mais comuns: mudanças bruscas de padrões de drenagem na mesma bacia hidrográfica; inflexões de drenagem em ângulos ortogonais e obtusos, como aquelas que redirecionam o curso principal dos rios Paraíba e Mamanguape (Figura 2A); e amplos meandros isolados e comprimidos, como os que ocorrem no curso terminal dos rios Paraíba e Mamanguape (Figura 2A).

A análise integrada combinando drenagem e relevo revelou uma complexidade de lineamentos morfoestruturais distribuídos na totalidade da área de estudo (Figura 2A). Na porção oeste desta área, de domínio do embasamento cristalino, registrou-se maior concentração de lineamentos morfoestruturais. Um número expressivo de lineamentos foi, ainda, registrado sobre a cobertura sedimentar a leste (Figura 2A). Lineamentos de direção E-W predominam em áreas de embasamento cristalino, seguido das modas principais N-S, NE-SW e, secundariamente, NW-SE (ver rosetas na Figura 2A). Áreas com predomínio de litologias da cobertura sedimentar registraram modas principais de direções E-W e NE-SW e, subordinadamente, NW-SE e N-S (Figura 2A). Modas similares a estas foram, também, observadas nas áreas dominadas por sedimentos aluviais que compreendem os vales fluviais dos rios Paraíba e Mamanguape. Nessas áreas, ocorreram modas principais de direções E-W e NE -SW, e moda secundária de direção NW-SE (Figura 2A).

\section{Caracterização geológica em subsuperfície e cronologia dos vales dos rios Paraíba e Mamanguape}

Informações de subsuperfície, combinadas com dados altimétricos, foram adicionalmente utilizadas no presente trabalho, a fim de reunir informações complementares visando verificar se os baixos cursos dos rios Paraíba e Mamanguape são confinados a sistemas de grabens, como já preliminarmente sugerido em publicações prévias (p.e., BRITO NEVES et al., 2004, 2009; BEZERRA et al., 2008, 2014). Sendo assim, foram elaborados dois transectos utilizando dados de sondagens e de descrições geológicas em campo (ver localização na Figura 1C). Estes transectos são representativos, não somente dos vales dos rios referidos, mas também de áreas adjacentes, cuja interpretação morfoestrutural levou à elaboração das seções geológicas apresentadas na Figura 3.

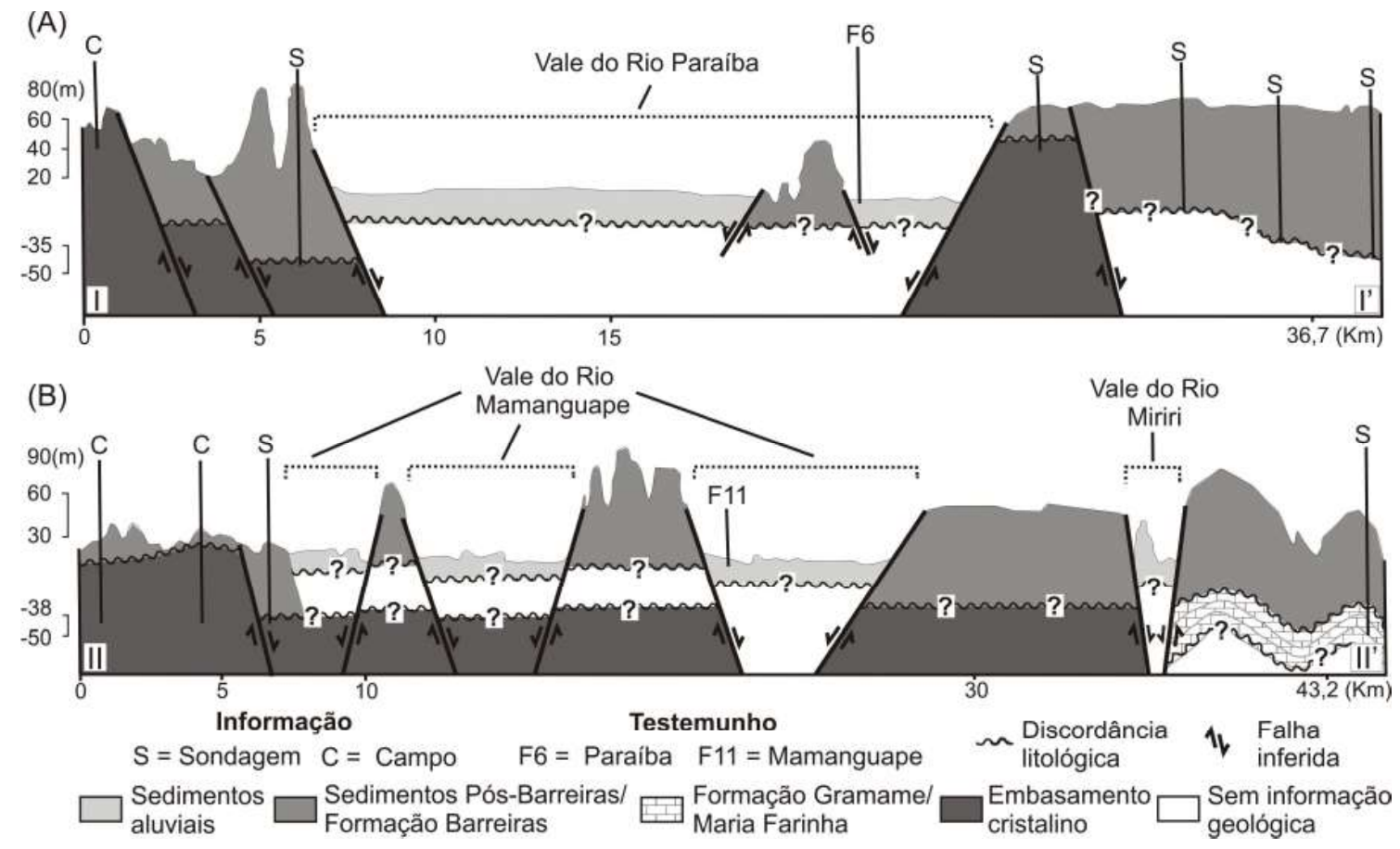

Figura 3 - Seções geológicas transversais aos vales dos rios Paraíba (A) e Mamanguape (B) elaboradas com base na correlação estratigráfica regional a partir de dados de subsuperficie e superficie (ver localização dos transectos na Figura 1C). 
Os dois transectos analisados situam-se em áreas dominadas por rochas de cobertura sedimentar e, subordinadamente, do embasamento cristalino précambriano (Figura 1C). De forma geral, observa-se variação expressiva nas espessuras dos estratos sedimentares em ambos os transectos (Figura 3). Como descrito abaixo, a correlação estratigráfica dos transectos deixa evidente, ainda, morfoestruturas em blocos elevados e rebaixados.

$\mathrm{O}$ transecto I-I' registra o vale do rio Paraíba (Figura 4A) na porção centro-sul da área de estudo. Este transecto possui $35,7 \mathrm{~km}$ de extensão e foi elaborado com base em cinco perfis de subsuperfície, um afloramento e um testemunho de sondagem rasa (Figura 3A). Nos primeiros $8 \mathrm{~km}$ do transecto, o embasamento cristalino, que aflora no extremo sul da área na mar- gem esquerda do rio Paraíba, está deslocado em várias dezenas de metros, aprofundando-se bruscamente sob forma de blocos escalonados sugestivos de falhas com mergulho para SE. É interessante observar que a espessura dos Sedimentos Pós-Barreiras subjacentes aumenta bruscamente de cerca de $40 \mathrm{~m}$ para $60 \mathrm{~m}$ (Figura 3A).

No vale do rio Paraíba, registram-se sedimentos aluvionares de espessuras desconhecidas (Figura 3A). Um perfil litoestratigráfico raso foi obtido nesses depósitos, o qual revelou uma sucessão de camadas de areias médias a finas, por vezes com granodecrescência ascendente, que se intercalam progressivamente com camadas de argila cinza, maciça (ver perfil F6 na Figura 5A). Para o topo, essas últimas litologias passam a ser dominantes, o que contribuiu para configurar tendência geral granodecrescente ascendente, indicativa de
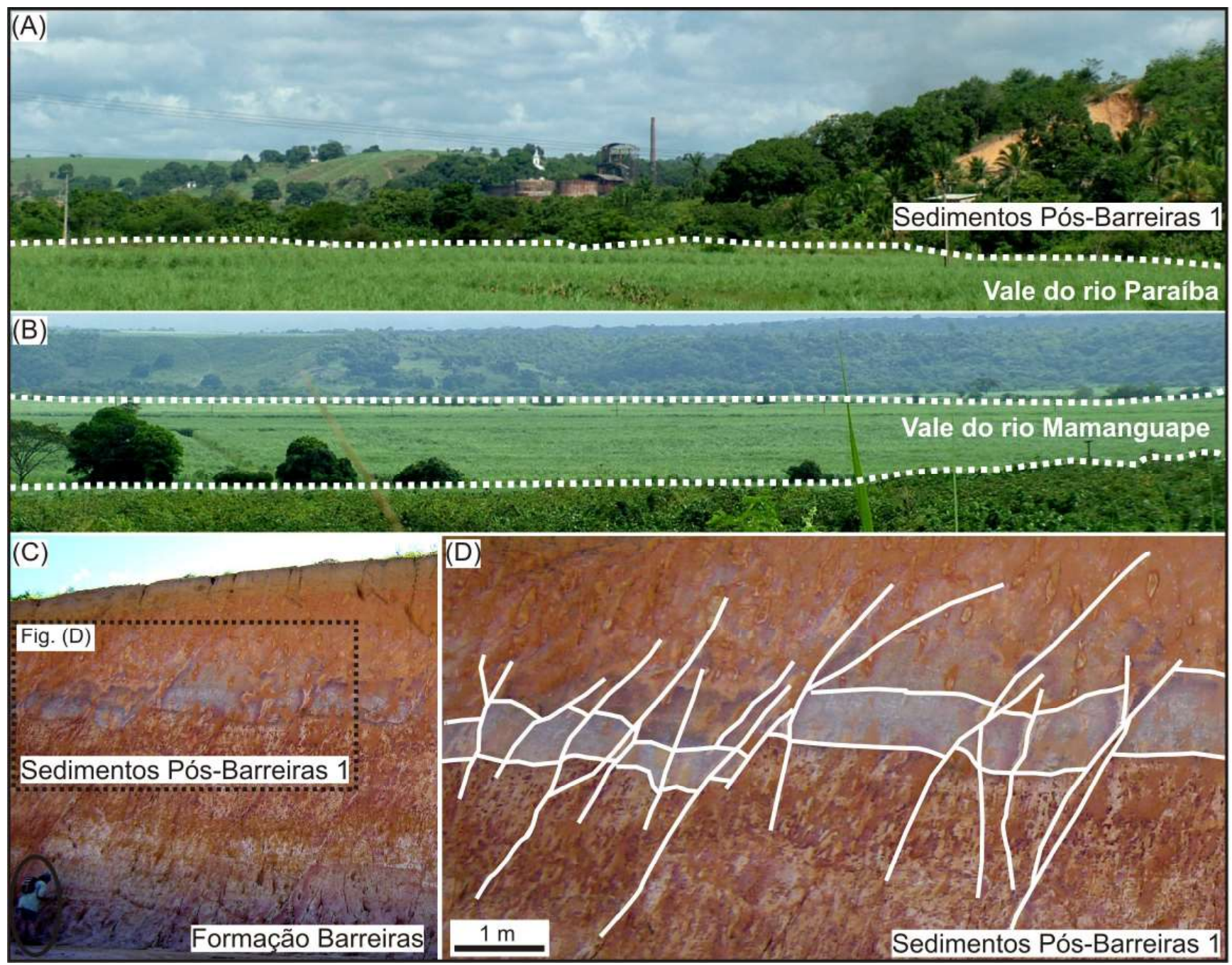

Figura 4 - Vales dos rios Paraiba (A) e Mamanguape (B), norte da Bacia Paraiba (linha tracejada branca = limite entre o vale fluvial e margens adjacentes). (C,D) Vista geral (C) e detalhe (D) de afloramento em área do entorno do vale do rio Mamanguape, onde a Formação Barreiras e os Sedimentos Pós-Barreiras 1 são deslocados por uma abundância de falhas sub-verticais (circulo preto em C indica pessoa para escala). 
diminuição de energia do fluxo com o tempo. Datações radiogênicas para amostras de depósitos argilosos desse perfil revelaram idades de $6.204-6.300(4,75 \mathrm{~m})$, $5.992-6.183(3,15 \mathrm{~m})$ e $969-1.007$ anos cal BP $(0,35$ m) (Tabela 1). Inversões de idades foram obtidas para amostras coletadas nas profundidades de $1,75 \mathrm{~m}$ e 1,95 $\mathrm{m}$, correspondentes a 6.636 - 6.752 e $9.479-9.537$ anos cal BP (Figura 5A), o que se deve provavelmente à presença de matéria orgânica derivada do retrabalhamento de sedimentos subjacentes. Em superfície, o local testemunhado corresponde à planície de inundação, dominada por argila preta (Figura 5B).

Os depósitos aluvionares do rio Paraíba são interrompidos por alto topográfico proeminente formado por depósitos correspondentes aos Sedimentos Pós-Barreiras/Formação Barreiras (ver alto topográfico no interior do vale na Figura 3A). Este é atribuído a um morro testemunho provavelmente formado por deslocamento de falhas dentro do vale do rio Paraíba. É interessante notar, ainda, que esse morro é limitado, em superfície, por uma série de lineamentos alinhados na direção NE-SW (Figuras 1C e 2A).

(A)
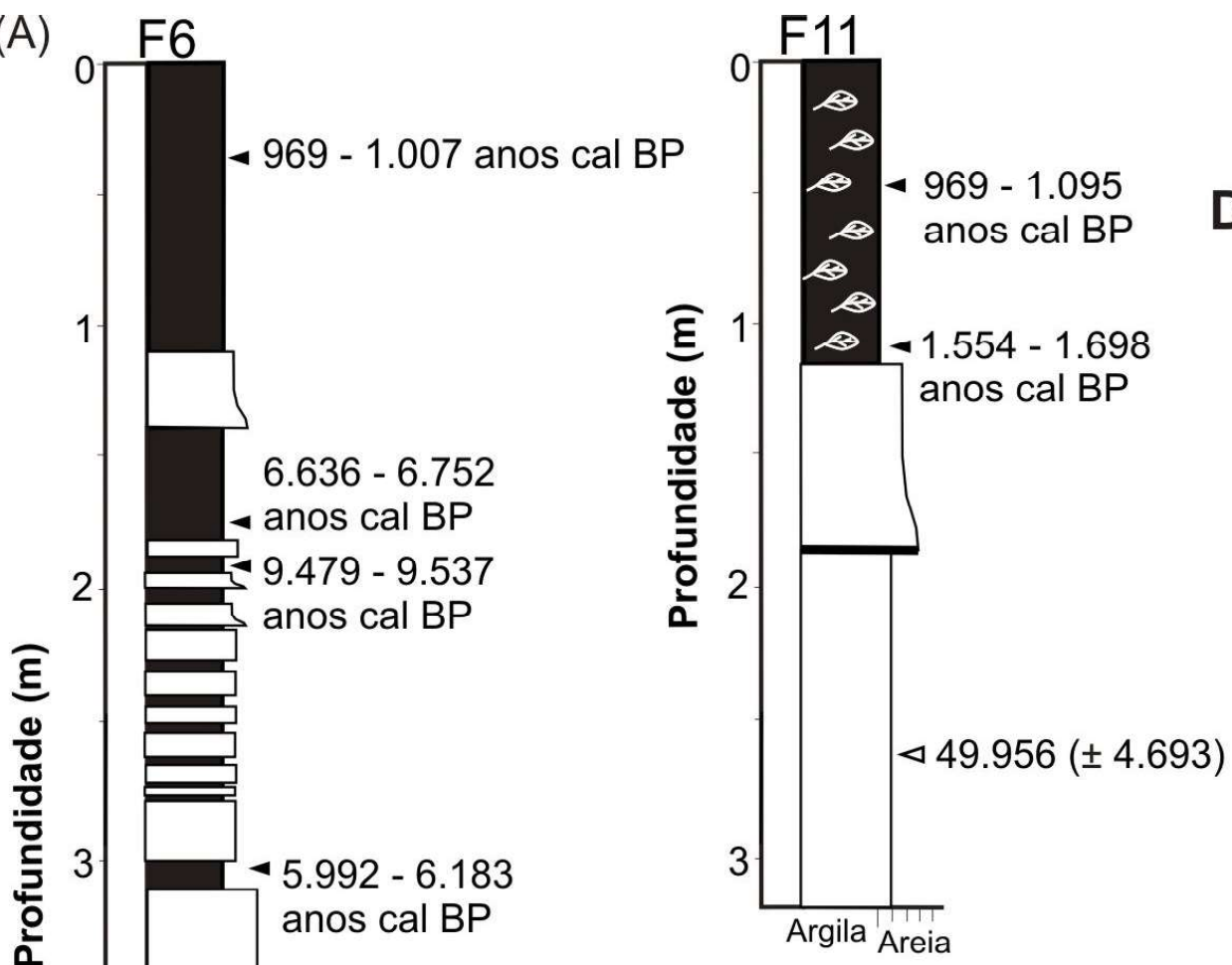

Datação de amostra

- Radiocarbono

$\triangleleft \mathrm{LOE}$

$\square$ Areia maciça

$\square$ Argila maciça

\&urfa
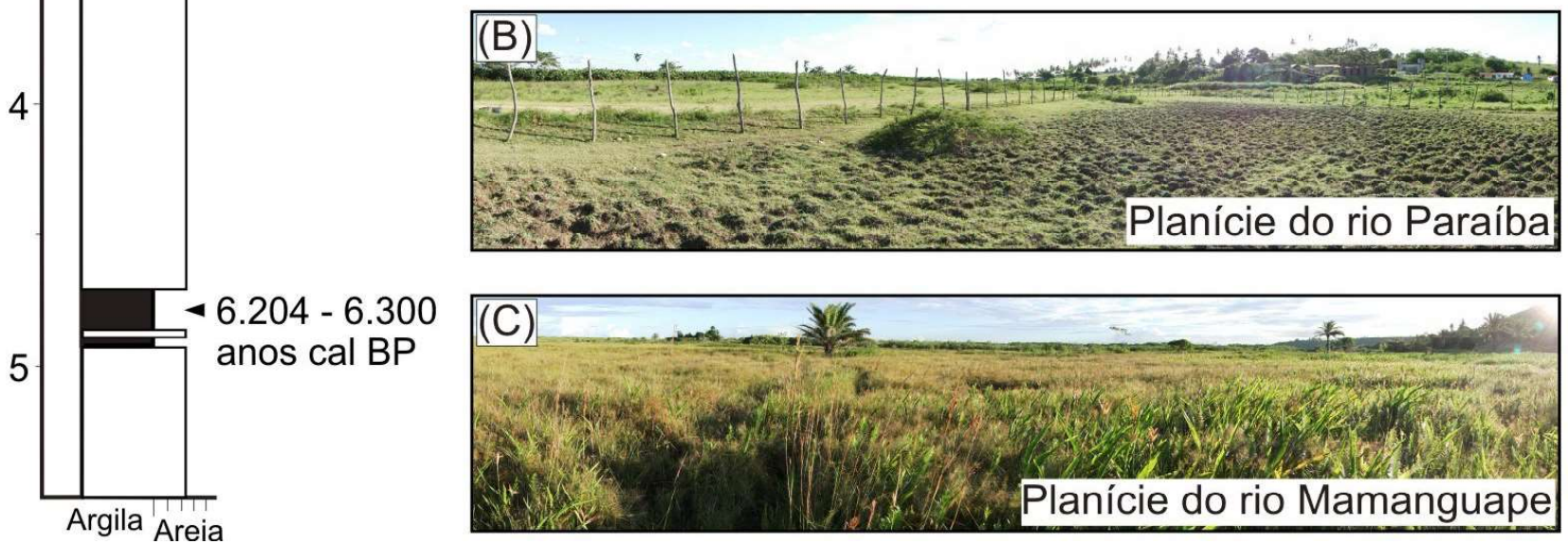

Figura 5 - (A) Perfis litoestratigráficos representativos dos estágios finais de preenchimento dos vales dos rios Paraiba (F6) e Mamanguape (F11) (ver localização nas Figuras 1C e 3). (B-C) Registros fotográficos da planície dos rios Paraíba (B) e Mamanguape (C). 
Na margem direita do rio Paraíba, o embasamento cristalino está em posição elevada, tendo sido registrado a aproximadamente $50 \mathrm{~m}$ de altitude, sendo sobreposto por camada delgada de depósitos pertencentes aos Sedimentos Pós-Barreiras/Formação Barreiras (Figura 3A). Esses depósitos continuam para leste, com aumento significativo de suas espessuras, ao mesmo tempo em que não houve registro das rochas do embasamento cristalino até a profundidade de pelo menos $50 \mathrm{~m}$. Tal situação é compatível com a presença de falha, como inferido na Figura 3A.

O transecto II-II', que registra o vale do rio Mamanguape no norte da área de estudo (Figura 4B), possui 41,2 km de extensão e foi elaborado com base em dois perfis de sondagens, dois afloramentos e um testemunho de sondagem rasa (Figura 3B). Os primeiros $7 \mathrm{~km}$ de transecto correspondem à margem esquerda do rio Mamanguape, onde foi registrado embasamento cristalino em posição elevada, i.e., até cerca de $25 \mathrm{~m}$ de altitude. Essas rochas são sobrepostas, de forma discordante, por camada delgada de Sedimentos Pós-Barreiras/Formação Barreiras. A espessura desses estratos sedimentares aumenta bruscamente nas margens do vale, ao mesmo tempo em que o embasamento cristalino é rebaixado à profundidade de $38 \mathrm{~m}$ abaixo da superfície. Isto sugere a ocorrência de falha com mergulho para NE, como mostrado na Figura 3B.

Tabela 1: Idades obtidas pela técnica de datação por radiocarbono em amostras derivadas de testemunhos de planície dos rios Paraíba (F6) e Mamanguape (F11).

\begin{tabular}{|c|c|c|c|c|c|}
\hline Perfil & $\begin{array}{l}\text { Localização } \\
\text { (Lat / Long) }\end{array}$ & Altitude (m) & $\begin{array}{c}\text { Profundidade } \\
\text { (m) }\end{array}$ & $\begin{array}{c}\text { Idade } \\
\text { Convencional }\end{array}$ & $\begin{array}{c}\text { Idade Calibrada } \\
\text { (anos cal BP) } \\
\text { (2-sigma) }\end{array}$ \\
\hline \multirow{5}{*}{ F6 } & \multirow{5}{*}{$\begin{array}{l}07^{\circ} 05^{\prime} 20^{\prime \prime} \mathrm{S} / \\
34^{\circ} 57^{\prime} 33^{\prime \prime} \mathrm{W}\end{array}$} & \multirow{5}{*}{4} & 0,35 & $1.102,9 \pm 0,3$ & $969-1.007$ \\
\hline & & & 1,75 & $5.870 \pm 30$ & $6.636-6.752$ \\
\hline & & & 1,95 & $8.510 \pm 30$ & $9.479-9.537$ \\
\hline & & & 3,15 & $5.300 \pm 30$ & $5.992-6.183$ \\
\hline & & & 4,75 & $5.450 \pm 30$ & $6.204-6.300$ \\
\hline \multirow{2}{*}{$* \mathrm{~F} 11$} & \multirow{2}{*}{$\begin{array}{l}06^{\circ} 45^{\prime} 50^{\prime \prime} \mathrm{S} / \\
34^{\circ} 58^{\prime} 22^{\prime \prime} \mathrm{W}\end{array}$} & \multirow{2}{*}{4} & 0,55 & $1.140 \pm 30$ & $969-1.095$ \\
\hline & & & 1,1 & $1.710 \pm 30$ & $1.554-1.698$ \\
\hline
\end{tabular}

* Amostra de base desse perfil foi também submetida à datação por LOE $(U(\mathrm{ppm})=1.774 \pm 0.0 ; \mathrm{Th}(\mathrm{ppm})=9.822 \pm 0.0 ; \mathrm{K}$ $(\%)=0.152 \pm 0.0 ;$ Número de alíquotas utilizadas $=14 ;$ Overdispersion $(\%)=24,2 ;$ Dose Equivalente $(G y)=65 \pm 4 ;$ Taxa de Dose Anual $(G y / k a)=1,3 \pm 0.0$; Idade Média (anos) = 49.956 \pm 4.693).

Assim como no vale do rio Paraíba, os sedimentos aluvionares do vale do rio Mamanguape são interrompidos bruscamente por dois altos topográficos constituídos de depósitos sedimentares relacionados com os Sedimentos Pós-Barreiras/Formação Barreiras (Figura 3B). É possível que o embasamento cristalino continue em subsuperfície entre os rios Mamanguape e Miriri, porém essas rochas desaparecem completamente na margem direita desse último rio, sendo substituídas por rochas carbonáticas da Formação Gramame/ Maria Farinha (Figura 3B). Nesse local, é notável o relevo ondulado sobre os Sedimentos Pós-Barreiras/ Formação Barreiras (Figura 3B), contrariamente às áreas adjacentes da margem esquerda do rio Miriri, onde o relevo é dominantemente plano. Com base em comparações de dados de outras publicações (p.e.,
ROSSETTI et al., 2009; ANDRADES FILHO, 2014), sabe-se que as unidades carbonáticas, bem como os estratos neógenos e pleistocênicos sobrejacentes, estão dobrados e, por isto, atribuiu-se o relevo ondulado da margem direita do rio Miriri a dobras, como ilustrado na Figura 3B. Exposições geológicas, quando disponíveis em áreas do entorno do vale do rio Mamanguape, revelam falhas de rejeitos consideráveis (Figura 4C-D) em depósitos contendo principalmente Sedimentos Pós -Barreiras 1 e, secundariamente, a Formação Barreiras.

Um perfil litoestratigráfico (ver localização do perfil F11 na Figura 1C) representativo da sedimentação quaternária superficial do vale do rio Mamanguape indicou intervalo delgado de areia fina/muito fina, bem selecionada e quartzosa, que grada para cima a turfas argilosas (Figura 5A). Hoje, o local testemunhado 
corresponde a um ambiente de pântano (Figura 5C), cujo desenvolvimento se iniciou a, pelo menos, 1.554 - 1.698 anos cal BP, tendo continuado até pelo menos 969 - 1.095 anos cal BP (Figura 5A). Entretanto, idade obtida por LOE para as areias da base desse testemunho registrou idade de $49.956 \pm 4.693$ anos, ou seja, bem mais antiga que os depósitos arenosos do rio Paraíba.

\section{Discussão}

Os resultados obtidos no presente trabalho atestam o uso favorável de técnicas e produtos de sensoriamento remoto na análise morfoestrutural da área de estudo. O uso de MDE-SRTM de resolução espacial de $30 \mathrm{~m}$ e de variáveis geomorfométricas foi apropriado para a análise do relevo e drenagem em escalas regional e de detalhe. Técnicas de relevo sombreado, paleta circular em níveis de cinza no caso da variável orientação de vertentes e paleta de cores a partir da estratificação dos valores de elevação no MDE-SRTM foram essenciais como operações auxiliares, o que permitiu melhor visualização das morfologias de interesse, favorecendo a extração da drenagem e lineamentos. A análise desses dois elementos morfoestruturais, bem como a interpretação de seções geológicas, permitiram evidenciar que atividades tectônicas foram importantes na construção do relevo da área de estudo, conforme discutido abaixo.

\section{Elementos morfoestruturais}

A análise da rede de drenagem reuniu dados compatíveis com áreas sujeitas a deformações tectônicas. Anomalias de drenagem, evidenciadas por canais com inflexões em ângulos retos a obtusos, como as registradas ao longo dos rios Paraíba e Mamanguape (Figura 2A), são comumente associadas a terrenos com controle estrutural, o que sugere captura de drenagem por estruturas tectônicas (p.e., HOWARD, 1967; DEFFONTAINES e CHOROWICZ, 1991). Segmentos retilíneos atribuídos a lineamentos de drenagem sugerem encaixe dos rios ao longo de linhas de falhas. Reativações tectônicas cenozóicas poderiam ter sido responsáveis pelas frequentes capturas e encaixe desses rios, como constatado em outras áreas da Bacia Paraíba (BRITO NEVES et al., 2004, 2009; BEZERRA et al., 2008, 2014; ANDRADES FILHO e ROSSETTI, 2012b).

Meandros isolados e comprimidos, como os registrados nos cursos terminais dos rios Paraíba e Mamanguape (Figura 2A), sugerem ajustes locais frente à movimentação de blocos tectônicos (HOWARD, 1967; DEFFONTAINES e CHOROWICZ, 1991; SUMMERFIELD, 1991). Essa interpretação é compatível com o fato dessas anomalias ocorrerem em áreas cuja morfologia sugere vales gerados por tectônica distensiva (p.e., BRITO NEVES et al., 2004, 2009; BEZERRA et al., 2008, 2014). Causa tectônica é a mais provável no caso particular dessas anomalias, levando em consideração, ainda, a alta sinuosidade registrada nos baixos cursos desses rios. Isto porque, mudança no gradiente de rios por subsidência tectônica pode ocasionar em aumento da sinuosidade de canais fluviais, como registrado nos sistemas fluviais da porção centro-oeste dos Estados Unidos (p.e., ADAMS, 1980; DOORNKAMP, 1986).

A maior expressividade de lineamentos de orientação E-W nas áreas do embasamento cristalino (Figura 2A) é compatível com a orientação similar de antigas zonas de cisalhamento précambrianas, que incluem falhas de direções predominantemente E-W a ENE-WSW (BRITO NEVES et al., 2004; BEZERRA et al., 2014). Lineamentos de direções principais E-W e NE-SW, registrados na cobertura sedimentar, sugerem reativações de estruturas pré-existentes do embasamento cristalino, onde tais orientações foram também observadas (BRITO NEVES et al., 2009; BEZERRA et al., 2014) (Figura 2A). Lineamentos de direções secundárias NW-SE também estão associados com reativações de estruturas pré-existentes do embasamento précambriano. Reativações de falhas de orientações similares foram registradas na porção sudoeste da bacia do rio Paraíba, onde ocorre o graben de Cariatá (BEZERRA et al., 2008).

$\mathrm{O}$ direcionamento similar dos lineamentos ao se comparar terrenos com predomínio de rochas do embasamento cristalino a oeste e de cobertura sedimentar a leste, sugere reativação de falhas pré-existentes. Isto é mostrado, ainda, pela concordância desses lineamentos com a orientação de falhas regionais (comparar Figuras $1 \mathrm{C}$ e 2A). O fato das áreas da porção oeste dessa bacia, onde predominam rochas do embasamento cristalino, terem revelado maior número e densidade de lineamentos relativamente às áreas da porção leste (Figura 2A), é devido possivelmente à sua idade mais antiga.

$\mathrm{O}$ registro de controle tectônico dos sistemas de drenagem, não apenas da Bacia Paraíba, mas também de outras bacias sedimentares marginais do litoral 
nordestino, tem sido crescente (ANDRADES FILHO e ROSSETTI, 2012b; MAIA e BEZERRA, 2013, 2014; ALVES e ROSSETTI, 2015). Nessas áreas, a ocorrência expressiva de padrões anômalos, anomalias de drenagem e lineamentos com direções compatíveis com estruturas tectônicas em áreas do embasamento cristalino e em terrenos sedimentares adjacentes, suporta reativações de estruturas antigas do embasamento, principalmente de falhas transcorrentes (BEZERRA et al., 2014; LIMA et al., 2016), em tempos geológicos mais recentes.

\section{Análise das seções geológicas}

A análise das seções geológicas aqui descritas sugere que os vales dos rios Mamanguape e Paraíba tiveram sua instalação controlada por fator tectônico. Essa interpretação é consistente com o fato dos depósitos sedimentares neógenos e quaternários (i.e., Formação Barreiras e Sedimentos Pós-Barreiras, respectivamente) terem espessuras variáveis a curtas distâncias em subsuperfície, em geral sendo mais espessas em direção aos vales. As rochas do embasamento cristalino também mostram desníveis de várias dezenas de metros em curtas distâncias em direção ao centro dos vales. Tal distribuição das unidades geológicas é mais consistente considerando um contexto geológico que inclui deslocamentos verticais ao longo de falhas. O padrão de variação de espessuras das unidades geológicas transversalmente aos vales dos rios Paraíba e Mamanguape, bem como em áreas adjacentes, deve-se, mais provavelmente, a um conjunto de falhas principalmente normais de rejeitos consideráveis (Figuras 3 e 4).

A correlação estratigráfica regional baseada no modelo de deslocamento de blocos de falha proposto no presente trabalho condiz com a morfologia da região estudada, caracterizada por altos e baixos topográficos em geral coincidentes com a ocorrência de horsts e grabens, respectivamente (Figuras 2B-C e 3). Propõe-se, portanto, que os trechos terminais dos rios Paraíba e Mamanguape são confinados a depressões tectônicas formadas por abatimento de blocos (Figura 6). Interpretação similar já havia sido previamente apresentada na literatura com base apenas em dados morfológicos (p.e., FURRIER et al., 2006; BEZERRA et al., 2008, 2014; BRITO NEVES et al., 2009). Além disso, dados geológicos obtidos para outras áreas da Bacia Paraíba sugeriram falhas afetando as rochas do embasamento cristalino e a sucessão sedimentar sobrejacente (BRITO NEVES et al., 2004, 2009; BEZERRA et al., 2008, 2014). Assim, o mais provável é que as estruturas tectônicas sugeridas para os vales dos rios Mamanguape e Paraíba tenham sido formadas a partir de reativações de falhas pré-existentes em tempos geológicos relativamente recentes, isto é, durante a deposição da Formação Barreiras no Neógeno, ou, até mesmo, após a deposição dos Sedimentos Pós-Barreiras.

De acordo com os dados gerados, pode-se interpretar que os vales dos rios Mamanguape e Paraíba não se estabeleceram por efeito erosivo decorrente de causas climáticas ou de variações do nível do mar. Esses vales refletem zonas de subsidência pelo desenvolvimento de grabens, onde houve deposição de amplas planícies aluviais contendo sedimentação mais jovem que nas áreas adjacentes. Depósitos relacionados à Formação Barreiras e aos Sedimentos Pós-Barreiras expostos no interior desses vales, quando presentes, acham-se em posição topográfica mais alta e em contato brusco com os depósitos aluvionares, sendo atribuídos a horsts que permaneceram como "ilhas", enquanto sedimentos aluvionares foram sendo depositados em áreas deprimidas de seus entornos (Figura 6).

As estruturas tectônicas aqui interpretadas são compatíveis com o registro de estruturas já reconhecidas na literatura, sendo as mais expressivas (i) o alto do Mamanguape situado ao norte do rio homônimo (BARBOSA et al., 2003; BRITO NEVES et al., 2009); (ii) o horst do Tabuleiro do Santana, situado entre os vales dos rios Paraíba e Miriri (BRITO NEVES et al., 2009); e (iii) o alto estrutural do alto curso do rio Mumbaba, situado ao sul do rio Paraíba (BRITO NEVES et al., 2009). A existência dessas estruturas na Bacia Paraíba é consistente, ainda, com informações similares oriundas de outras bacias sedimentares marginais do litoral nordestino, onde tem sido crescente o registro de reativações tectônicas similares (MAIA e BEZERRA, 2013, 2014; BEZERRA et al., 2014).

A análise dos perfis litoestratigráficos rasos representativos dos estágios finais de preenchimento sedimentar dos vales dos rios Paraíba e Mamanguape (Figura 5) permitiu extrair informações importantes a respeito da evolução quaternária desses dois vales. Assim, os depósitos arenosos da base do perfil do rio Paraíba (ver perfil F6 na Figura 5A) foram interpretados como representativos de fase em que esse rio 


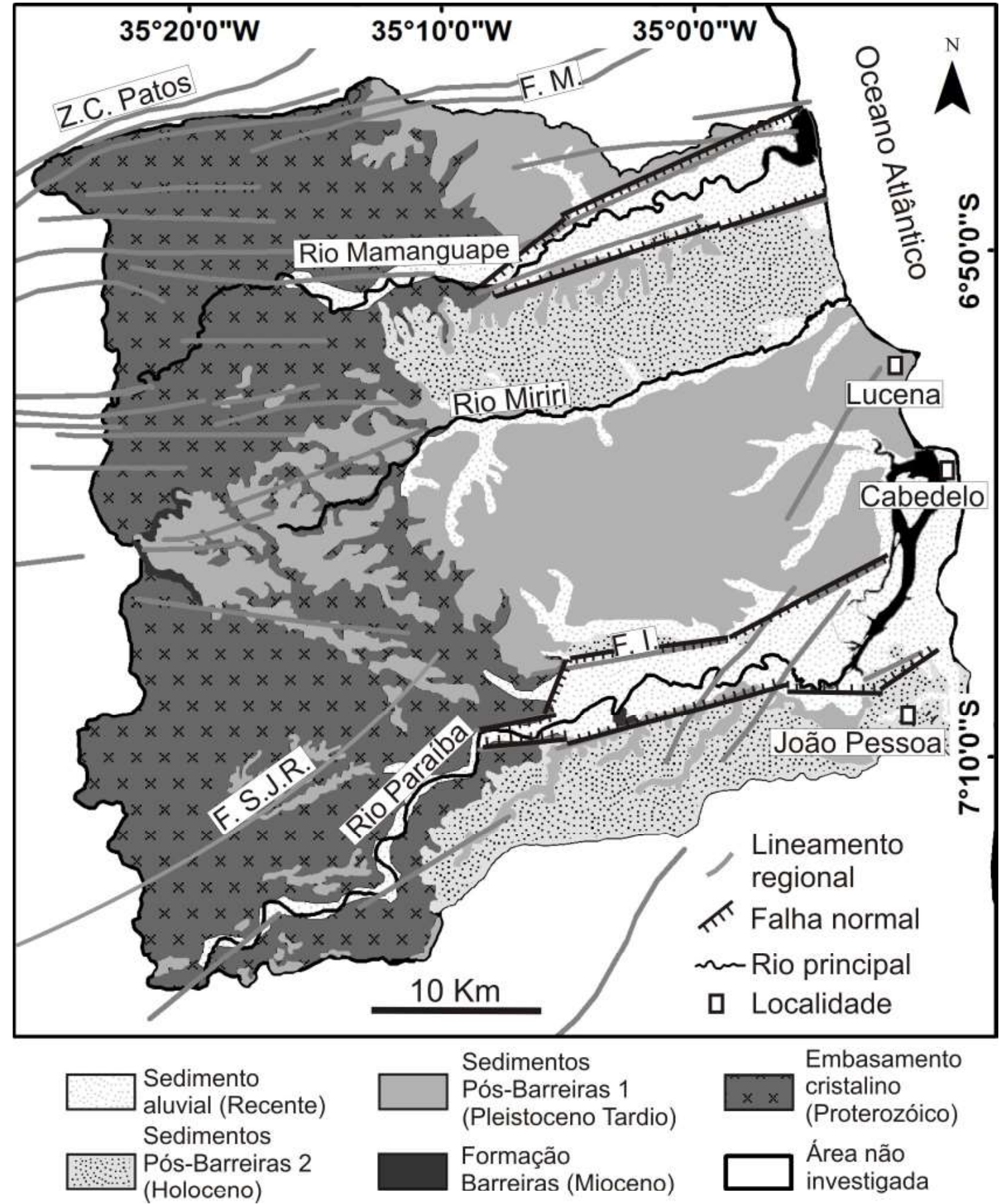

Figura 6 - Grabens dos rios Paraiba e Mamanguape, com localização das unidades geológicas e dos lineamentos regionais principais (Z.C. Patos = zona de cisalhamento Patos; F.M. = Falha de Mamanguape; F.S.J.R. = Falha de São José dos Ramos; e F.I. = Falha de Itabaiana). Fonte: Mapa geológico: adaptado de Rossetti et al. (2012); lineamentos regionais: adaptado de Barbosa et al. (2003), Brito Neves et al. (2004, 2009), Bezerra et al. (2008, 2014).

tinha energia mais elevada relativamente a seu curso atual, quando esse rio se estendia em grande parte onde, posteriormente, houve a instalação da planície de inundação. De acordo com as idades obtidas por radiocarbono, essa situação ocorreu até entre 6.204 -
6.300 e 5.992 - 6.183 anos cal BP. Por outro lado, há, ainda, a possibilidade de que esses depósitos arenosos sejam representativos de algum rio secundário do sistema de drenagem do rio Paraíba. Com o tempo, esses depósitos arenosos cessaram de ser acumulados 
e a sedimentação no vale passou a ser representada somente por argilas, que se depositaram a partir de suspensões na planície de inundação (Figura 5A). Depósitos argilosos do topo desse perfil, com idade de 969 - 1.007 anos cal BP, atestam deposição a partir de suspensões em áreas da planície de inundação durante momentos de cheia.

Por outro lado, o registro de idade LOE bem mais antiga, i.e., $49.956 \pm 4.693$ anos, nos depósitos arenosos representativos da base do perfil do rio Mamanguape (ver perfil F11 na Figura 5A) indica desenvolvimento diferenciado do rio Paraíba. Assim, a sedimentação arenosa no rio Mamanguape finalizou muito antes que no rio Paraíba. Com base nos dados apresentados, é possível sugerir que o rio Paraíba permaneceu com energia maior até o Holoceno. Essa energia decaiu somente a poucas centenas de anos atrás. Para o rio Mamanguape, a grande diferença de idade LOE de $49.956 \pm 4.693$ anos para 1554-1698 anos cal BP obtida em apenas $1 \mathrm{~m} \mathrm{e}$ a presença de contato erosivo, sugerem hiato deposicional, antes do qual predominava sedimentação arenosa. A natureza pantanosa atual e as camadas de areia e turfa registradas em subsuperfície indicam que, após ter permanecido sob condições erosivas, a sedimentação retornou a esse rio. A sedimentação se deu inicialmente por fluxos mais energéticos, com decréscimo de energia nos últimos estágios evolutivos, isto é, a partir de 1.554 -1.698 anos cal BP.

\section{Conclusões}

As técnicas e produtos de sensoriamento remoto utilizadas no presente trabalho foram eficientes para a análise morfoestrutural das bacias dos baixos cursos dos rios Paraíba e Mamanguape, cuja interpretação morfoestrutural revelou importantes evidências neotectônicas. Esta análise, aliada à correlação geológica regional, confirmou que a instalação dos vales dos rios Paraíba e Mamanguape ocorreu em grabens. Com base nas unidades geológicas encontradas nas áreas dos vales e adjacências, sugere-se que essas estruturas tenham sido formadas no Neógeno, durante a deposição da Formação Barreiras, ou até mesmo, após a deposição dos Sedimentos Pós-Barreiras no Pleistoceno Tardio -Holoceno. Datações por radiocarbono e luminescência opticamente estimulada, representativas dos estágios finais de preenchimento dos vales dos rios analisados, revelaram registro sedimentar de idade mais antiga para o rio Mamanguape $(49.956 \pm 4.693)$ do que para o rio Paraíba (6.204 - 6.300 anos cal BP). Investigações futuras são necessárias visando o registro sedimentar em camadas mais profundas para melhor caracterizar a evolução quaternária desses vales fluviais.

\section{Agradecimentos}

Os autores agradecem à CAPES pela concessão de bolsa de mestrado ao primeiro autor, e à FAPESP pelo financiamento desta pesquisa (Projeto\#2012/06010-5).

\section{Referências Bibliográficas}

ADAMS, J. Active tilting of the United States midcontinent: Geodetic and geomorphic evidence. Geology, v. 8, p. 442-446, 1980.

ALMEIDA, F.F.M.; BRITO NEVES, B.B.; CARNEIRO, C.D.R. The origin and evolution of the South American Plataform. Earth Science Reviews, v. 50, n.1-2, p. 77-111, 2000.

ALVES, F.C.; ROSSETTI, D.F. Análise morfoestrutural e neotectônica na porção norte da Bacia Paraíba (PB). Revista Brasileira de Geomorfologia, v.16, n.4, p.559-578, 2015.

ANDRADES FILHO, C.O.; ROSSETTI, D.F. Effectiveness of SRTM and ALOS-PALSAR data for identifying morphostructural lineaments in northeastern Brazil. International Journal of Remote Sensing, v. 33, n. 4, p. 1058-1077, 2012a.

ANDRADES FILHO, C.O.; ROSSETTI, D.F. Caracterização morfoestrutural da parte central emersa da bacia Paraíba (PB). Revista brasileira de geociências, v. 31, n. 1, p. 13-29, 2012 b.

ANDRADES FILHO, C.O. Evolução tectono-sedimentardar da Formação Barreiras e dos Sedimentos Pós-Barreiras, Bacia Paraíba, Nordeste do Brasil. 2014. Tese (Doutorado em Geoquímica e Geotectônica), Universidade de São Paulo (USP), São Paulo, 2014

ARAÚJO, V.D.; REYES-PERES, Y.A.; LIMA, R.O.; PELOSI, A.P.M.R.; MENEZES, L.; CÓRDOBA, V.C.; LIMA-FILHO, F.P. Fácies e sistemas deposicionais da Formação Barreiras na região da Barreira do Inferno, litoral oriental do Rio Grande do Norte. Geologia USP Série Científica, v. 6, n. 2, p. 43-50, 2006.

BARBOSA, J.A.; SOUZA, E.M.; LIMA FILHO, M.; NEUMANN, V.H. A estratigrafia da bacia Paraíba: uma reconsideração. Estudos Geológicos, v. 13, p. 89-108, 2003.

BEZERRA, F.H.R.; VITA FINZI, C. How active is a passive margin? Paleoseismicity in northeastern Brazil. Geology, 
Boulder, CO, v. 28, p. 591-594, 2000.

BEZERRA, F.H.R.; NEVES, B.B.B.; CORREA, A.C.B.; BARRETO, A.M.F.; SUGUIO, K. Late Pleistocene tectonicgeomorphological development within a passive margin - The Cariatá trough, northeastern Brazil. Geomorphology, v. 97, n.3-4, p. 555-582, 2008.

BEZERRA, F.H.R.; ROSSETTI, D.F.; OLIVEIRA, R.G.; MEDEIROS, W.E.; BRITO NEVES, B.B.; BALSAMO, F.; NOGUEIRA, F.C.C.; DANTAS, E.L.; ANDRADES FILHO, C.; GÓES, A.M. Neotectonic reactivation of shear zones and implications for faulting style and geometry in the continental margin of NE Brazil. Tectonophysics, v. 614, p. 78-90, 2014.

BRITO NEVES, B.B.; RICCOMINI, C.; FERNANDES, T.M.G.; SANT'ANNA, L.G. O sistema tafrogênico terciário do saliente oriental nordestino na Paraíba: um legado Proterozóico. Revista Brasileira de Geociências, v. 1, n. 34, p. 127-134, 2004.

BRITO NEVES, B.B.; ALBUQUERQUE, J.P.T.; COUTINHO, J.M.V.; BEZERRA, F.H.R. Novos dados geológicos e geofísicos para caracterização geométrica e estratigráfica da Sub-Bacia de Alhandra (sudeste da Paraíba). Geologia USP-Série Científica, v. 9 , n. 2, p. 63-87, 2009.

COMPANHIA DE PESQUISAS DE RECURSOS MINERAIS - CPRM. Fosfato de Miriri - estados de Pernambuco e Paraíba, Org. BARBOSA, J. A.; LEMOS, L. B. S. G, Informe de recursos minerais. Série Oportunidades Minerais - Exame Atualizado de Projeto, 11 Recife, 2001, 17 p.

DEFFONTAINES, B.; CHOROWICZ, J. Principles of drainage basin analysis from multisource data: application to the structural analysis of the Zaire Basin. Tectonophysics, v. 194, n. 3, p. 237-263, 1991.

DOORNKAMP, J.C. Geomorphological approaches to the study of neotectonics. Journal of the geological society, v. 143, p. 335-342, 1986.

FURRIER, M.; ARAUJO, M.E.; MENESES, L.F. Geomorfologia e tectônica da Formação Barreiras no Estado da Paraíba. Geologia USP - Série Científica, v. 6, n. 2, p. 61-70, 2006.

GANDINI, R.; ROSSETTI, D.F.; NETTO, R.G.; BEZERRA, F.H.R.; GÓES, A.M. Neotectonic evolution of the Brazilian northeastern continental margin based on sedimentary facies and ichnology. Quaternary Research, v. 82, p. 462-472, 2014.

HOWARD, A.D. Drainage analysis in geologic interpretation: a summation. American Association of Petroleum Geologists Bulletin, v. 51, n. 11, p. 2.246-2.259, 1967.

LIMA, J.C.F.; BEZERRA, F.H.R.; ROSSETTI, D.F.; BARBOSA,
J.A.; MEDEIROS, W.E.; CASTRO, D.L.; VASCONCELOS, D.L. Neogene-Quaternary fault reactivation influences coastal basin sedimentation and landform in the continental margin of NE Brazil. Quaternary Internacional, p.1-16, 2016.

LIMA FILHO, M.F.; BARBOSA, J.A.; SOUZA, E.M. Eventos tectônicos e sedimentares nas Bacias de Pernambuco e da Paraíba: implicações no quebramento do Gondwana e correlação com a Bacia do rio Muni. Revista de Geociências, v. 25, n. 1, p. 117-126, 2006.

MAIA, R.P.; BEZERRA, F.H.R. Tectônica Pós-Miocênica e controle estrutural de drenagem no rio Apodi-Mossoró, Nordeste do Brasil. Boletim da geografia, v. 31, n. 2, p. 57-68, 2013.

MAIA, R.P.; BEZERRA, F.H.R. Inversão neotectônica do relevo na Bacia Potiguar, Nordeste do Brasil. Revista Brasileira de Geomorfologia, v. 15, n. 1, p. 61-74, 2014.

MORAIS, R.M.O.; MELLO, C.L.; COSTA, F.O.; SANTOS, P.F. Fácies sedimentares e ambientes deposicionais associados aos depósitos da formação barreiras no Estado do Rio de Janeiro. Geologia USP Série Científica, v. 6, p. 19-30, 2006.

MURRAY, A.S.; WINTLE, A.G. Luminescence dating of quartz using an improved single-aliquot regenerative-dose protocol. Radiation Measurements, v. 32, n. 1, p. 57-73, 2000.

O'LEARY, D.W.; FRIEDMAN, J.D.; POHN, H.A. Lineament, linear, lineation: some proposed new standards for old terms. GSA Bulletin, v. 87, p. 1.463-1.469, 1976.

RABUS, B.; EINEDER, M.; ROTY, A.; BAMLER, R. The Shuttle Radar Topographic Mission: a new class of digital elevation models acquired by spaceborne radar. ISPRS Journal of Photogrammetry \& Remote Sensing, v. 57, p. 241-262, 2003.

ROSSETTI, D.F.; GÓES, A.M.; TRUCKENBRODT, W. A influência marinha nos sedimentos Barreiras. Boletim do Museu Paraense Emílio Goeldi (Série Ciências da Terra), v. 2, p. 17-29, 1990.

ROSSETTI, D.F.; VALERIANO, M.M.; BEZERRA, F.H.R.; BRITO NEVES, B.B.; GÓES, A.M. Caracterização morfológica da porção sul da Sub-bacia de Alhandra, Bacia Paraíba, com base em dados SRTM: contribuição na compreensão do arcabouço estrutural. In: Simpósio Brasileiro de Sensoriamento Remoto, 14. (SBSR), 2009, Natal. Anais... São José dos Campos: INPE, 2009. p. $3325-3332$.

ROSSETTI, D.F.; BEZERRA, F.H.; GÓES, A.M.; BRITO NEVES, B.B. Sediment deformation in Miocene and postMiocene strata, Northeastern Brazil: evidence for paleoseismicity 
in a passive margin. Sedimentary Geology, v. 235, p. 172-187, 2011a.

ROSSETTI, D.F.; BEZERRA, F.H.R.; GÓES, A.M.; VALERIANO, M.M.; ANDRADES FILHO, C.O.; MITTANI, J.C.R.; TATUMI, S.H.; BRITO NEVES, B.B. Late Quaternary sedimentation in the Paraíba Basin, Northeastern Brazil: landform, sea level and tectonics in Eastern South America passive margin. Palaeogeography, Palaeoclimatology, Palaeoecology, v. 300, p. 191-204, 2011 b.

ROSSETTI, D.F.; GÓES, A.M.; BEZERRA, F.H.; VALERIANO, M.M.; BRITO NEVES, B.B.; OCHOA, F.L. Contribution to the stratigraphy of the onshore Paraíba Basin, Brazil. Anais da Academia Brasileira de Ciência, v. 84, n. 2, p. 313-334, 2012.

ROSSETTI, D.F.; BEZERRA, F.H.; DOMINGUEZ, J.M.L. Late Oligocene-Miocene transgressions along the equatorial and eastern margins of Brazil. Earth-Science Reviews, v. 123, p. 87-112, 2013.

SUMMERFIELD, M.A. Global geomorphology: an introduction to the study of landforms. New York: Logman Scientific \& Technical, 1991. $537 \mathrm{p}$.

VALERIANO, M.M. Visualização de imagens topográficas. In: SIMPÓSIO BRASILEIRO DE SENSORIAMENTO REMOTO, 13. (SBSR), 2007, Florianópolis. Anais... São José dos Campos: INPE, 2007, p. 1.377-1.384.

VALERIANO, M.M.; ROSSETTI, D.F. Análise digital do padrão de coerência da orientação de vertentes em terrenos planos. In: Congresso da Associação Brasileira de Estudos do Quaternário, 13. (ABEQUA), 2011, Búzios. Anais... São Paulo: ABEQUA, 2011. p. 1-5.

VALERIANO, M.M., ROSSETTI, D.F. Topodata: Brazilian full coverage refinement of SRTM data. Applied Geography, v. 32, n. 2, p. 300-309, 2012.

WINTLE, A.G.; MURRAY, A.S. A review of quartz optically stimulated luminescence characteristics and their relevance in single-aliquot regeneration dating protocols. Radiation Measurements, v. 41, p. 369-391, 2006. 